Devel opment of 394. $6 \mathrm{GHz}$ CW Gyr ot r on ( Gyr ot r on FU CWII) for DNP/Pr ot on- NR at $600 \mathrm{Mrz}$

\begin{tabular}{|l|l|}
\hline 著者 & $\begin{array}{l}\text { I DEHARA T, OGAWA I, La AguSu, KANAMAK T, } \\
\text { M TSUDO S, SAI TO T, FUJI WARA T, TAKAHASH H }\end{array}$ \\
\hline $\begin{array}{l}\text { j our nal or } \\
\text { publ i cat i on t i t I e }\end{array}$ & $\begin{array}{l}\text { I nt er nat i onal J our nal of I nf } r \text { ar ed and } \\
\text { M I I i net er haves }\end{array}$ \\
\hline vol une & 28 \\
\hline number & 6 \\
\hline page $r$ ange & 433442 \\
\hline year & $2007-06$ \\
\hline URL & ht t p: //hdl . handl e. net /10098/1933 \\
\hline
\end{tabular}




\title{
Development of 394.6 GHz CW gyrotron (Gyrotron FU CW II) for DNP/proton-NMR at $600 \mathrm{MHz}$
}

\author{
T. Idehara, I. Ogawa, La Agusu, T. Kanamaki, S. Mitsudo, T. Saito \\ Research Center for Development of Far Infrared Region, University of Fukui \\ Bunkyo 3-9-1, Fukui-shi 910-8507, Japan \\ T. Fujiwara, H. Takahashi \\ Institute of Protein Research, Osaka University, \\ 3-2 Yamadaoka, Osaka, Japan
}

\begin{abstract}
Gyrotron FU CW II with an $8 \mathrm{~T}$ liquid He free superconducting magnet, the second gyrotron of the $\mathrm{THz}$ Gyrotron FU CW Series, has been constructed and the operation test was successfully carried out. It will be used for enhancing the sensitivity of $600 \mathrm{MHz}$ proton-NMR by use of Dynamic Nuclear Polarization (DNP). The designed operation mode of the gyrotron is $\mathrm{TE}_{2,6}$ at the second harmonic. The corresponding frequency is $394.6 \mathrm{GHz}$. The real operation frequency is $394.3 \mathrm{GHz}$ at $\mathrm{TE}_{06}$ mode, because of fabrication error of the diameter of the cavity. The operation is in complete $\mathrm{CW}$ at the output power of around $30 \mathrm{~W}$ or higher at the $\mathrm{TE}_{06}$ cavity mode. There are many other operation modes at the fundamental and the second harmonic. Typical output power of the fundamental and the second harmonic are higher than $100 \mathrm{~W}$ and $20 \mathrm{~W}$, respectively. The highest frequency observed up to the present is $443.5 \mathrm{GHz}$ at the second harmonic operation of $\mathrm{TE}_{6,5}$ mode. The measured results are compared with the theoretical consideration.
\end{abstract}

Key words: gyrotron, THz, DNP, NMR, CW operation, second harmonic

\section{Introduction}

Gyrotrons are useful and important high power radiation sources in millimeter to submillimeter wavelength range, which includes sub- $\mathrm{THz}$ and $\mathrm{THz}$ frequency region. Untill quite recently, we had no radiation source with high power and high stability in this frequency range. Gyrotrons appeared as high power radiation sources which cover the so-called ' $\mathrm{THz}$ 
gap'.

The major part of the gyrotron development began in 1970s for ultra-high power millimeter wave gyrotrons. These gyrotrons were used mainly for heating and current drive of fusion plasma. ${ }^{1)}$ The output power per one tube is $1.5 \mathrm{MHz}$ and the frequency is ranged from $140 \mathrm{GHz}$ to $170 \mathrm{GHz}$. The operation pulse width is extended up to $3000 \mathrm{sec}$.

The development of high frequency gyrotrons with high field superconducting magnets is rather a minor way of the gyrotron development. It was carried out in several research institutes, that is, IAP RAS, MIT, the University of Sydney and the University of Fukui. The frequency range of submillimeter waves is achieved in 1980s and 1990s by several gyrotrons in these institutions. $^{2)-7)}$

In the Research Center for Development of Far Infrared Region, University of Fukui (FIR FU), we have developed high frequency Gyrotron FU Series which consists of nine gyrotrons. Among them, in 1996, Gyrotron FU IVA achieved the frequency of $889 \mathrm{GHz}$ with the output power of around $100 \mathrm{~W}$. The frequency corresponds to the wavelength of $377 \mu \mathrm{m} .{ }^{8)}$ This frequency was the long-term world record for high frequency operation of gyrotron untill 2006. Recently, our pulsed gyrotron with a high field pulse magnet achieved the breakthrough of 1 $\mathrm{THz}$ by the second harmonic operation at the field intensity of $19.1 \mathrm{~T} .{ }^{9)}$

Now, we are developing the THz Gyrotron FU CW Series, which will cover sub- $\mathrm{THz}$ to $\mathrm{THz}$ range and operate in a complete $\mathrm{CW}$ mode. Gyrotron FU CW I with a $12 \mathrm{~T}$ liquid He free magnet has already been developed and succeeded in fundamental operation at $300 \mathrm{GHz}$ with the output power of $1.75 \mathrm{~kW} .{ }^{10), 11)}$ It is being applied to material processing and the development of new medical technology.

The second gyrotron in the FU CW series, Gyrotron FU CW II with an $8 \mathrm{~T}$ liquid He free magnet, has also been constructed and succeeded in operation test. It will be used for enhancement of NMR sensitivity by use of DNP. In this manuscript, the details of the gyrotron are presented. The design of the gyrotron on the basis of computer simulation is described in the next section. ${ }^{11)}$ The whole experimental device including a demountable gyrotron tube constructed following the design is introduced in the third section. Experimental results and comparison with the computer simulation results are presented in the fourth section and finally the contents described in the manuscript will be summarized in the fifth section.

\section{Design of the gyrotron tube on the basis of computer simulation}

The goal of this design is to successfully generate several tens watts of $\mathrm{CW}$ power at the 
second harmonic operation of $\mathrm{TE}_{2,6}$ mode at $394.6 \mathrm{GHz}$, with a power level which is sufficient to perform biological experiments using sensitivity-enhanced nuclear magnetic resonance (NMR) through dynamic nuclear polarization (DNP).

It was well-known that the second harmonic modes are much more difficult to be excited than the fundamental mode because of mode competition with fundamental modes. The mode competition of $\mathrm{TE}_{26}$ mode with neighbor fundamental mode $\mathrm{TE}_{23}$ was studied in detail experimentally. ${ }^{4)}$ This means that we have much experience about this and are a good understanding of how to excite this mode.

The gyrotron is designed for several-day-long operation at a low level of output power. It is designed for $25 \mathrm{keV}$ or less electron beam energy. The electron gun for generating helical electron beam is a triode type electron gun. The cathode radius is $4.5 \mathrm{~mm}$. In practice, the electron beam parameters such as the beam radius and the velocity pitch factor can be experimentally tuned by using a gun coil installed around the electron gun through changing the magnetic compression rate, that is, the ratio between axial magnetic fields at the cavity and cathode. The gun coil produces the maximum magnetic field of $0.183 \mathrm{~T}$.

The resonant interaction structure of gyrotron is a cylindrical cavity that is optimized for the $\mathrm{TE}_{2,6}$, second harmonic mode at $394.6 \mathrm{GHz}$ using a cold cavity (electron beam absent) simulation code. Fig. 1 shows the crosssection of a cylindrical cavity consisting of a straight section of $15 \mathrm{~mm}$ in length and circular cross-section which has a radius of $2.36 \mathrm{~mm}$ joined to a

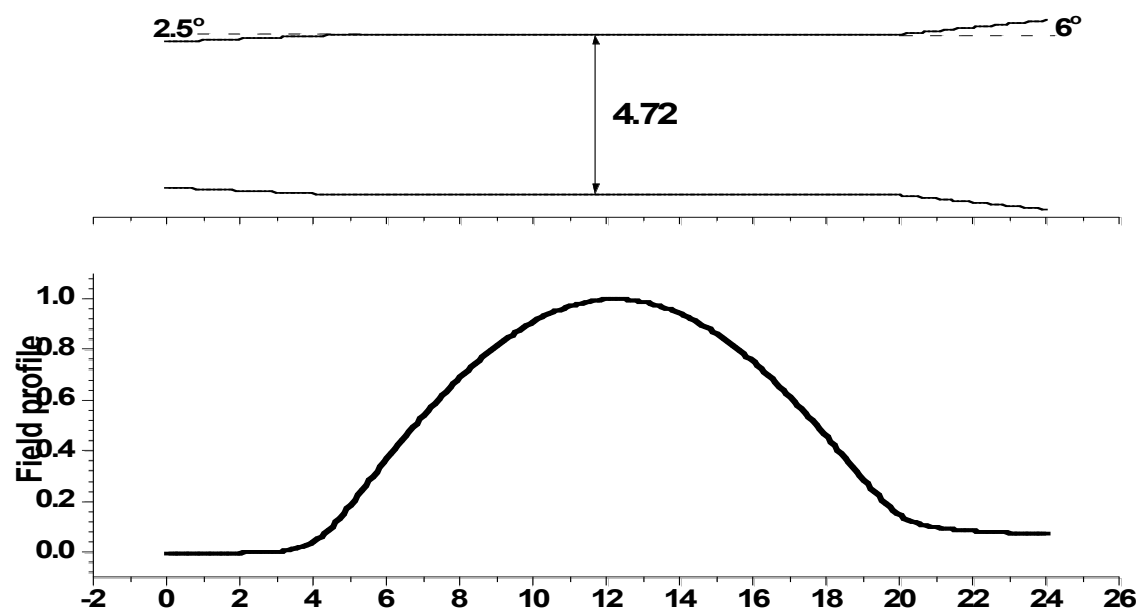

Fig. 1 Cross-section of a $395 \mathrm{GHz}$ gyrotron cavity with the axial field profile for the second harmonic $\mathrm{TE}_{2,6}$ mode. Input taper: $L_{1}=4 \mathrm{~mm}, \theta_{1}=2.5^{\circ}$; Middle section $R=2.36 \mathrm{~mm}, L=15 \mathrm{~mm}$; output taper: $L_{2}=4 \mathrm{~mm}, \theta_{2}=6.0^{\circ}$. 
linear up-taper section with a slope angle of $6.0^{\circ}$ at the outlet of the cavity and a linear down-taper section with the angle of $2.5^{\circ}$ at the entrance of the cavity. The lower trace in Fig. 1 shows the axial profile of the designed mode, $\mathrm{TE}_{2,6}$. The material of the gyrotron cavity is copper.

Fig. 2 demonstrates the starting current of all modes in the cavity in the magnetic field range of 6.7 $\mathrm{T}$ to $7.5 \mathrm{~T}$. It is seen that there are several candidates for single mode operations at the second harmonic, if the magnetic field intensity is adjusted carefully. For single mode operation of $\mathrm{TE}_{2,6}$ and $\mathrm{TE}_{0,6}$ at the second harmonic, the most dangerous competitor is $\mathrm{TE}_{2,3}$ mode at the fundamental. Mode competition among these modes has been simulated. It was confirmed as the results that both modes $\mathrm{TE}_{2,6}$ and $\mathrm{TE}_{0,6}$ can overcome $\mathrm{TE}_{2,3}$ and excited in single modes.

The design details were already published in the previous paper. ${ }^{12)}$

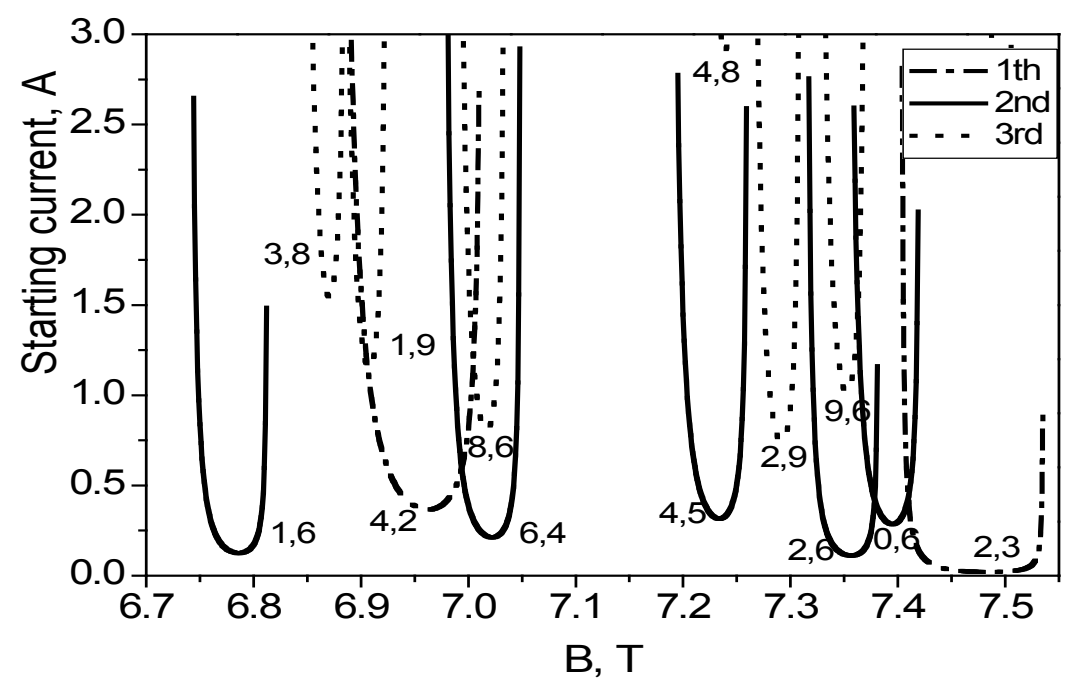

Fig. 2 The starting currents for the resonant cavity with the magnetic field range from $6.7 \mathrm{~T}$ to 7.55 T. The fundamental, second, and the third harmonics correspond to the broken, solid, and dotted lines, respectively

\section{Experimental apparatus}

The gyrotron FU CW II device consists of a demountable gyrotron tube, a magnet system consisting of a $8 \mathrm{~T}$ liquid $\mathrm{He}$ free superconducting magnet and three additional coils in the gun region with a power supply, two high voltage power supplies for the cathode and the anode of electron gun and a power supply for a filament of the gun.

The gyrotron tube is installed on the center axis of the air bore of the cryostat whose diameter 
is $100 \mathrm{~mm}$. The tube is demountable. Therefore, all of the components, that is, an electron gun, a cavity system, a collector and a window, can be replaced, when we need to change any of them. The electron gun is a triode magnetron injection gun. The radius of the emitting area is $4.5 \mathrm{~mm}$. A cavity is located in the center of the superconducting magnet coil. The maximum field intensity at the cavity region is $8 \mathrm{~T}$ and the variation in the spherical region with the diameter of $10 \mathrm{~mm}$ is less than 1 percent. Two water jackets are installed on the cavity and the collector regions in order to cool down these regions during $\mathrm{CW}$ operation. The output window is made of a sapphire disk whose diameter and thickness are $33 \mathrm{~mm}$ and $2.5 \mathrm{~mm}$, respectively. The inner diameter of the collector is $28 \mathrm{~mm}$. It operates as an oversized waveguide for transmitting an output power from the outlet of cavity to the window. After the window, a circular waveguide with a diameter of $28 \mathrm{~mm}$ is connected to the collector cylinder across the sapphire window disk.

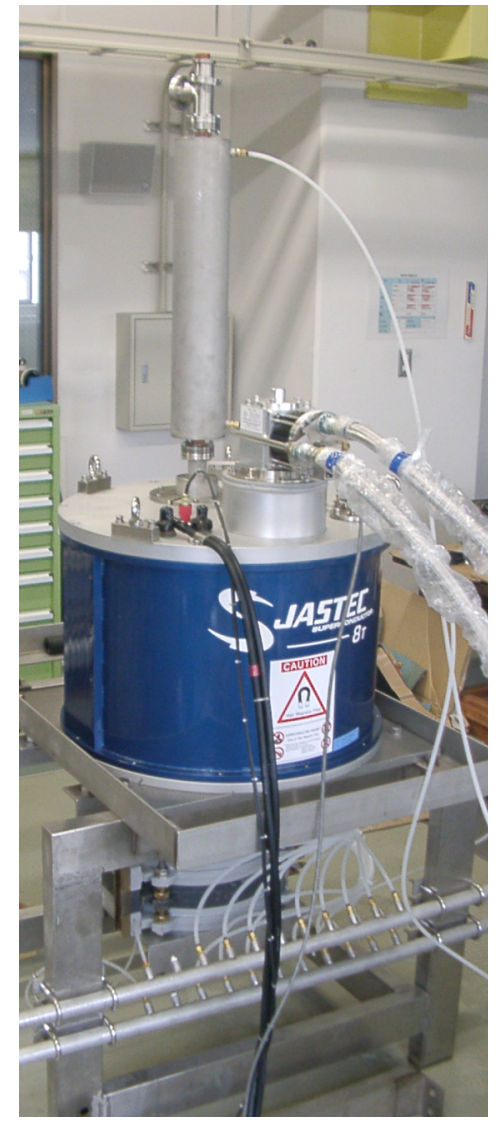

Photo.1 The appearance of Gyrotron FU CW II

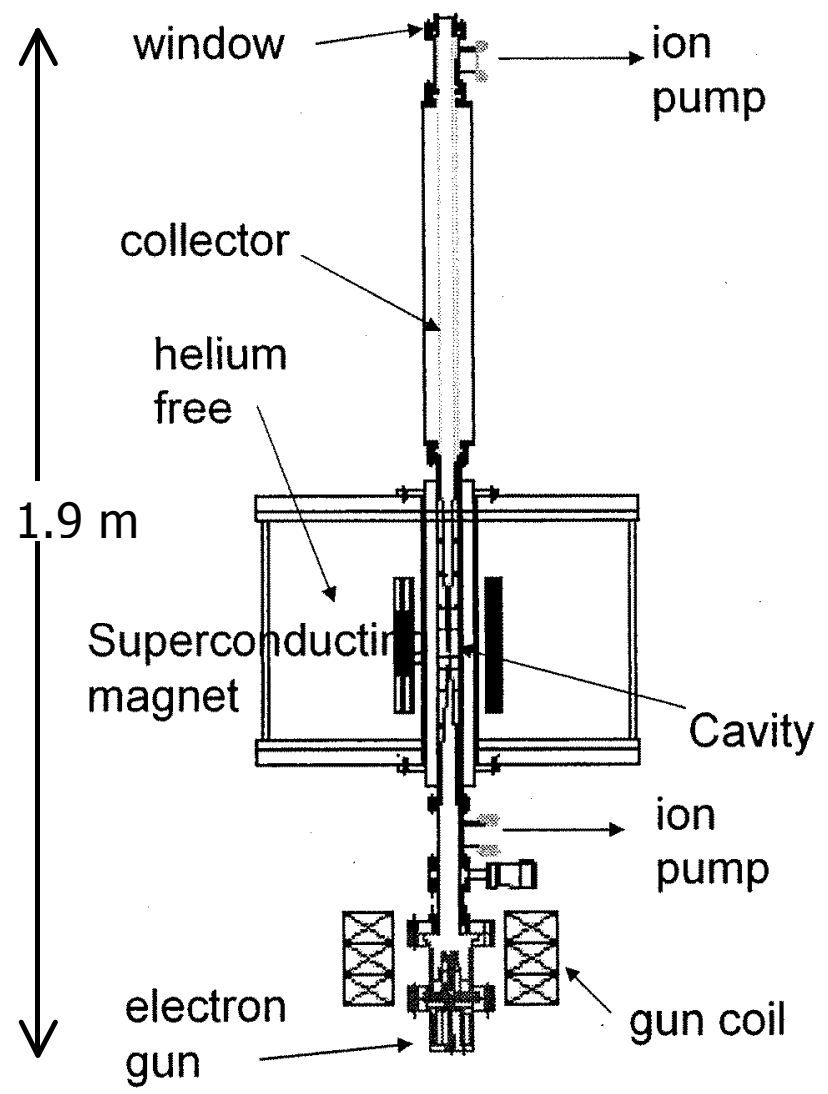

Fig. 3 Installation of a demountable tube on the center axis of an $8 \mathrm{~T}$ liquid He free magnet 
Photo. 1 shows the appearance of the gyrotron tube and the magnet system, and Fig. 3 shows a view of the cross section. A demountable tube is installed on the axis of the magnet system consisting of an $8 \mathrm{~T}$ superconducting magnet and three additional coils.

Three pieces of normal copper coils surround an electron gun in order to control the field intensity at the gun region and then to adjust the best value injection point of beam electrons at the entrance of a cavity. In addition, the anode voltage is controlled in order to adjust the best condition of the pitch factor. These are quite important to achieve highly efficient operation of the gyrotron. In almost all cases, a mirror ratio of the field configuration, that is, the ratio between the field intensities at the cavity region and the gun region, can vary from 40 to 80.

The magnetic field intensity at the cavity region varies from $2 \mathrm{~T}$ to $8 \mathrm{~T}$, the beam electron energy from $8 \mathrm{kV}$ to $15 \mathrm{kV}$ and the beam current from $200 \mathrm{~mA}$ to $400 \mathrm{~mA}$. The gyrotron is operated at both pulsed and continuous modes. In the case of pulsed operation mode, repetition rate is typically $1 \mathrm{~Hz}$ and the pulse width varies from $1 \mathrm{~ms}$ to $500 \mathrm{~ms}$. After completing the vacuum inside the tube in a pulsed operation, the operation is changed to the continuous mode.

\section{Experimental results and comparison with the computer simulation results}

First of all, we have measured radiation power from the gyrotron as function of magnetic field intensity. The operation is in a pulsed mode. The repetition rate is $1 \mathrm{~Hz}$ and the duty ratio typically 10 to 30 percent. The pulsed output radiation power is sampled and recorded on an XY recorder. Fig. 4 shows the results. In the upper trace, radiation power measured directly after the window is traced as a function of magnetic field intensity, while in the lower trace, radiation power coming out through a high-pass filter with a small circular waveguide is traced as a function of the field intensity. The diameter and the cutoff frequency are $0.7 \mathrm{~mm}$ and $251 \mathrm{GHz}$, respectively. Therefore, the upper trace includes both the fundamental and the second harmonic radiations, while the lower trace only second harmonics. As seen in the figure, the widths of radiation peak in the lower trace (second harmonics) are much narrower than those in the upper trace (mainly fundamentals). Some of the radiation peaks in the lower trace are seen in the upper trace at the same magnetic field intensity. This means that these second harmonic operations occur in single modes without mode competition with any fundamental operation modes. These features are predicted by the computer simulation demonstrated in our previous 
paper, ${ }^{12)}$ and are very important for our high frequency, harmonic gyrotron. Almost all radiation peaks appearing in the both traces correspond to cavity modes whose mode numbers have been identified by observed frequencies.

Next, the operation mode switched from pulsed mode to $\mathrm{CW}$ mode. Output power just after the output window for all of observed radiation peaks is measured by use of a water load. The results are shown in Tables 1 and 2. Observed powers are distributed in the ranges of 100 to 200 $\mathrm{W}$ for fundamental operations and 10 to $30 \mathrm{~W}$ for second harmonic operations. All of these powers are obtained by single mode $\mathrm{CW}$ operations even in the cases of second harmonics. Therefore, these are useful and convenient for its application to many new technologies in the

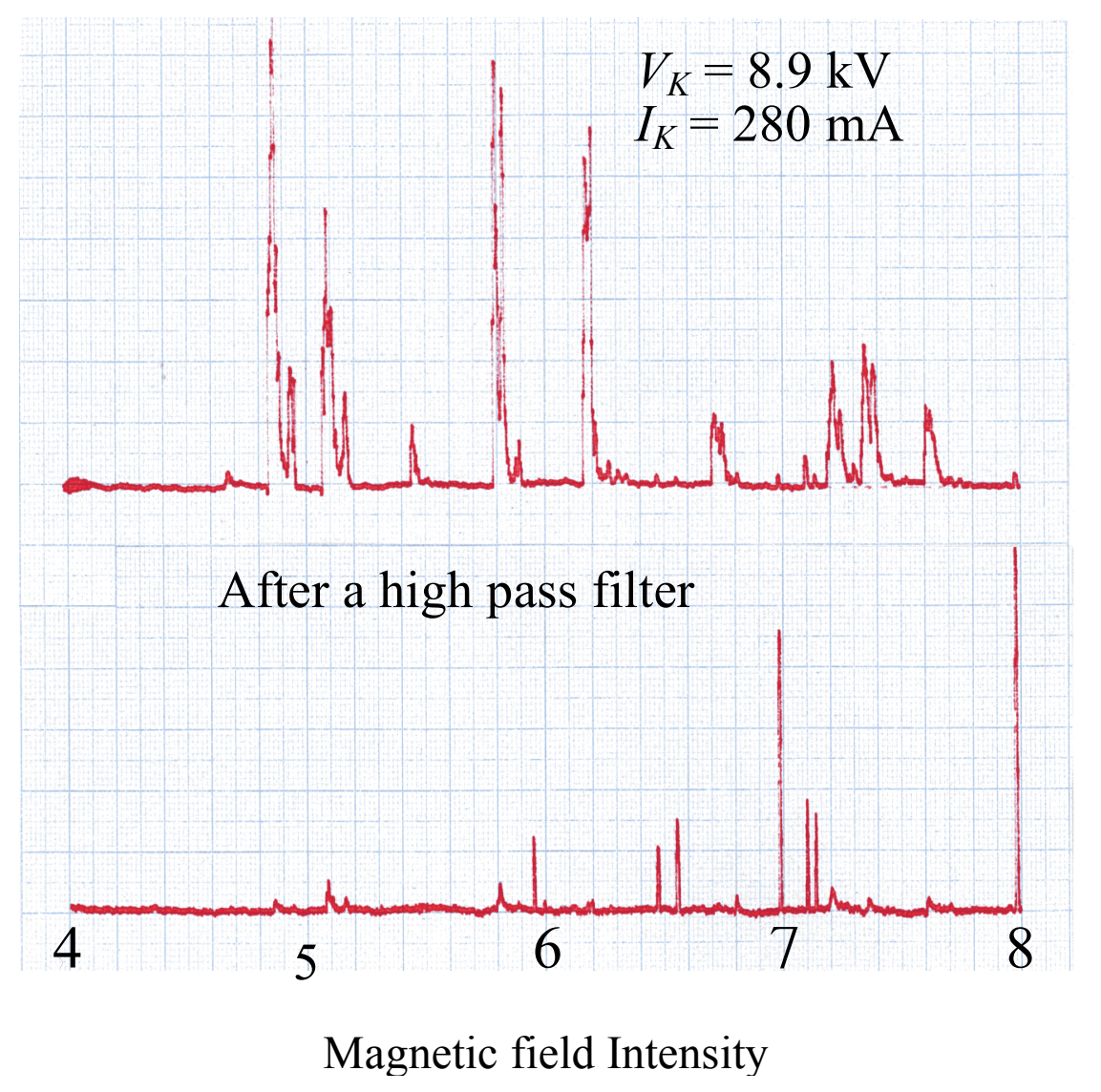

Fig. 4 Radiation power from the gyrotron FU CW II as functions of magnetic field intensity. Upper trace: Radiation power measured just after the output window. Lower trace: Radiation power coming out through the high pass-filter with a thin circular waveguide whose diameter is $0.7 \mathrm{~mm}$. (The corresponding cutoff frequency is $251 \mathrm{GHz}$.) 
sub-THz frequency range.

The frequencies for all of radiation peaks in both the fundamental and the second harmonic operations are measured by a spectrum analyzer with a heterodyne detection system which consists of a synthesizer as a local oscillator and a harmonic mixer. From this measurement, the cavity modes can be identified and listed in both tables. In the tables, azimuthal and radial mode numbers $\mathrm{m}$ and $\mathrm{n}$ are shown. The results of frequency measurement are shown as $f_{\text {meas }}$ in Tables 1 and 2 with the calculated frequencies as $f_{\text {cal }}$ for the designed cavity.

Table 1 Operation parameters of gyrotron FU CW II at the fundamentals $(\mathrm{N}=1)$. Here, are demonstrated the main field intensity $B_{0}$ in $\mathrm{T}$ at the cavity region, observed output power $P$ in $\mathrm{W}$, acceleration voltage for electrons $V_{\mathrm{b}}$ in $\mathrm{kV}$, electron beam current $I_{\mathrm{b}}$ in $\mathrm{mA}$, beam efficiency $\mu$ in $\%$, calculated frequency $f_{\text {cal }}$ in $\mathrm{GHz}$ for cavity mode, measured frequency $f_{\text {meas }}$ in $\mathrm{GHz}$ and corresponding cavity mode number m,n.

\begin{tabular}{|l|c|c|c|c|c|c|c|l|}
\hline$B_{0}, \mathrm{~T}$ & $P, \mathrm{~W}$ & $V_{\mathrm{b}, \mathrm{kV}}$ & $I_{\mathrm{b}}, \mathrm{mA}$ & $\mu, \%$ & $f_{\text {cal }} \mathrm{GHz}$ & $f_{\text {meas }}, \mathrm{GHz}$ & $\mathrm{TE}_{\mathrm{m}, \mathrm{n}}$ & $\mathrm{N}$ \\
\hline 3.86 & 130 & 9.74 & 260 & 5.1 & 108.10 & 107.48 & 1,2 & 1 \\
\hline 4.84 & 210 & 9.68 & 320 & 6.8 & 138.84 & 134.95 & 2,2 & 1 \\
\hline 5.10 & 95 & 9.68 & 320 & 3.1 & 142.79 & 141.28 & 0,2 & 1 \\
\hline 5.83 & 100 & 9.72 & 280 & 3.7 & 162.27 & 161.34 & 3,2 & 1 \\
\hline 6.19 & 158 & 9.69 & 310 & 5.3 & 172.79 & 171.73 & 1,3 & 1 \\
\hline 6.74 & 126 & 9.71 & 290 & 4.5 & 187.87 & 186.65 & 4,2 & 1 \\
\hline 7.22 & 180 & 9.79 & 210 & 8.8 & 201.75 & 200.43 & 2,3 & 1 \\
\hline 7.38 & 170 & 9.82 & 180 & 9.6 & 205.87 & 204.54 & 0,3 & 1 \\
\hline 7.62 & 181 & 9.81 & 190 & 9.7 & 212.87 & 211.40 & 5,2 & 1 \\
\hline
\end{tabular}

Table 2 Operation parameters of gyrotron FU CW II at the second harmonics $(\mathrm{N}=2)$. Demonstrated operation parameters are the same as those in Table1.

\begin{tabular}{|l|l|c|c|c|c|c|c|l|}
\hline$B_{0}, \mathrm{~T}$ & $P, \mathrm{~W}$ & $V_{\mathrm{b}}, \mathrm{kV}$ & $I_{\mathrm{b}}, \mathrm{mA}$ & $\mu, \%$ & $f_{\text {cal }, \mathrm{GHz}}$ & $f_{\text {meas }}, \mathrm{GHz}$ & $\mathrm{TE}_{\mathrm{m}, \mathrm{n}}$ & $\mathrm{N}$ \\
\hline 6.9860 & 17.9 & 9.62 & 380 & 0.49 & 388.20 & 386.03 & 4,5 & 2 \\
\hline 7.15 & 24 & 13.66 & 340 & 0.52 & 394.6 & 392.25 & 2,6 & 2 \\
\hline 7.19 & 32 & 13.675 & 325 & 0.72 & 396.69 & 394.27 & 0,6 & 2 \\
\hline 7.98 & 5.3 & 9.62 & 380 & 0.14 & 443.51 & 440.93 & 6,5 & 2 \\
\hline
\end{tabular}


As seen in the tables, all of measured frequencies are lower than calculated frequencies by about 0.57 percent. This differences come from the fabrication error of the cavity radius. The error is also 0.57 percent and real size of the radius is larger by $14 \mu \mathrm{m}$. The frequency of $\mathrm{TE}_{0,6}$ mode at the second harmonic opration shown in Table 2 is close to the principally designed frequency, that is, $394.6 \mathrm{GHz}$ of $\mathrm{TE}_{26}$ mode. The output power is larger than $30 \mathrm{~W}$. This means that the output power of this mode is available as a radiation source for $600 \mathrm{MHz} \mathrm{DNP} /$ proton-NMR. Many other observed frequencies are also useful for sub-THz spectroscopy, for example, ESR measurement, plasma diagnostics and so on. All frequencies observed up to the present are plotted as functions of magnetic field intensity in Fig. 5.

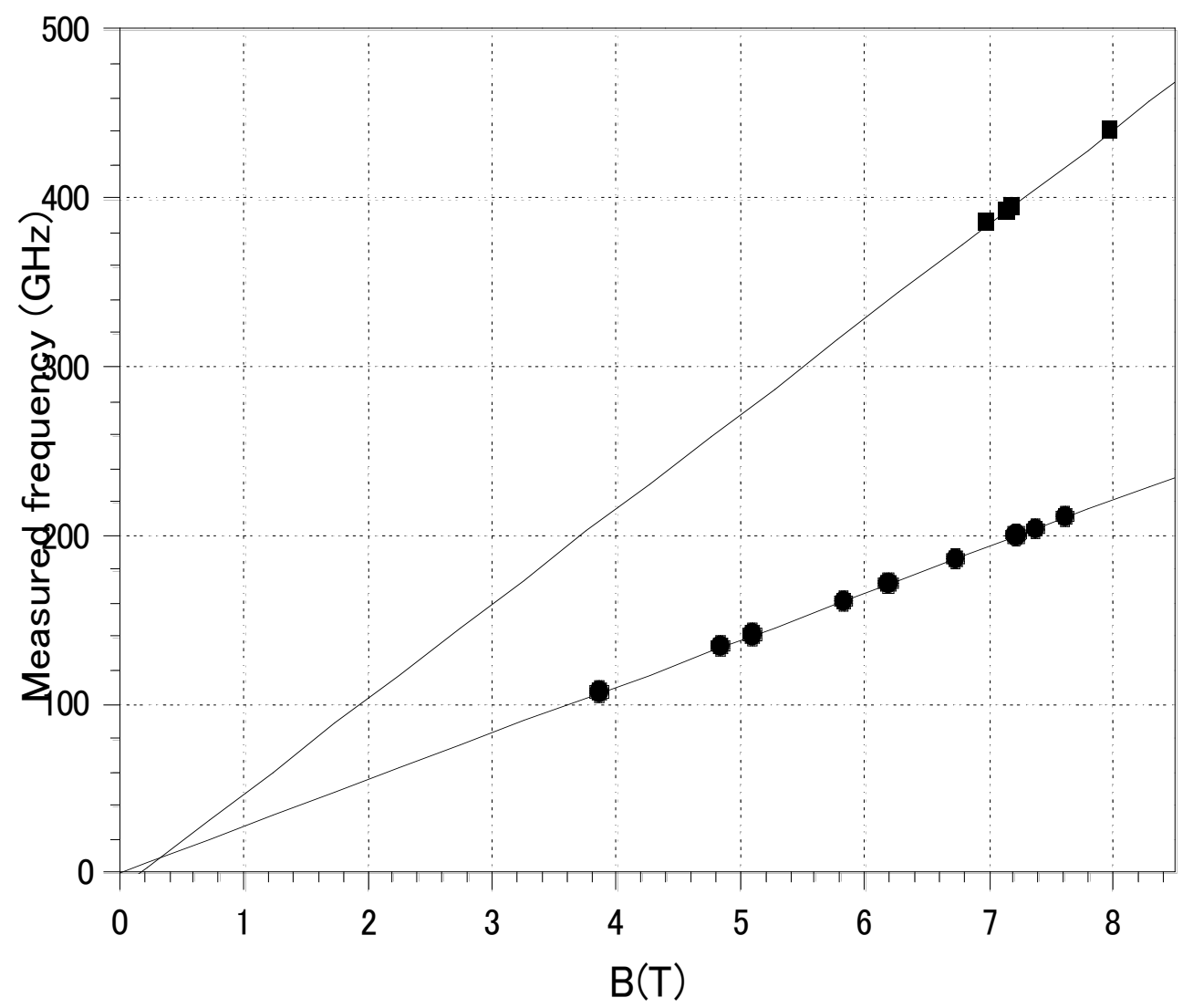

Fig. 5 All of observed frequencies as functions of magnetic field intensity.

The beam efficiency $\mu$ is estimated by dividing the measured output power $P$ by the input power of electron beam $V_{\mathrm{b}} \cdot I_{\mathrm{b}}$ and demonstrated in Tables 1 and 2. It ranges from 3 to 10 percent for fundamental operations and from 0.1 to 0.7 percent for second harmonic operations. 
The efficiency at the fundamentals is quite high even at low voltage operation lower than 10 $\mathrm{kV}$.

Next, we tried to measure the dependency of output power $P$ on the beam current $I_{\mathrm{b}}$ for several operation modes, $\mathrm{TE}_{2,3}$ at the fundamental, $\mathrm{TE}_{2,6}$ and $\mathrm{TE}_{0,6}$ at the second harmonic. The beam electron energy is kept at the constant values of around $9 \mathrm{keV}$ and $14 \mathrm{keV}$, respectively. The measurement results are shown in Fig. 6. It seems that output power for all modes is saturated even at low beam current $I_{\mathrm{b}}$ around $300 \mathrm{~mA}$. In the present case, the beam electron energy is low: around $9 \mathrm{keV}$ for fundamentals and around $14 \mathrm{keV}$ for second harmonics. The low saturation level may result from such low beam electron energy. Hopefully, it will be increased by increased beam electron energy $V_{\mathrm{b}}$.

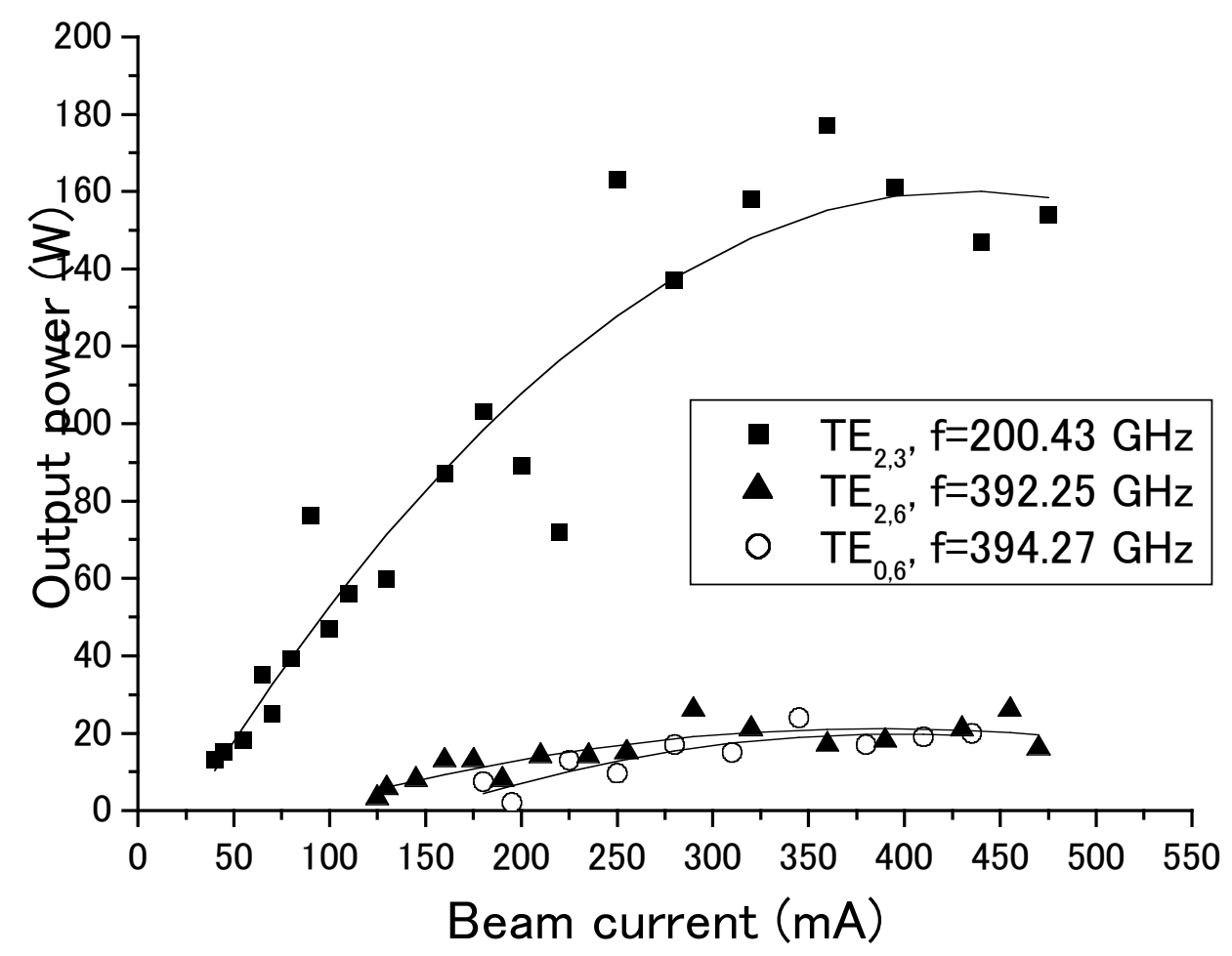

Fig. 6 Observed output power $P$ for $\mathrm{TE}_{2,3}$ mode at the fundamental, $\mathrm{TE}_{2,6}$ and $\mathrm{TE}_{0,6}$ modes at the second harmonics as functions of beam current $l b$.

Fig. 7 shows a typical frequency spectrum for $\mathrm{TE}_{0,6}$ mode operation at the second harmonic. (The frequency is $394.27 \mathrm{GHz}$.) A heterodyne detection system with a synthesizer as a local oscillator and a harmonic mixer are used for the measurement. The frequency is quite stable. 
The fluctuation is an order of $10 \mathrm{kHz}$. The quality of the spectrum is also excellent. As seen in Fig. 5, the half value width is several $\mathrm{kHz}$ and the width for $10 \mathrm{~dB}$ lower is around $10 \mathrm{kHz}$. This means that gyrotron FU CW II can be available for spectroscopy with high frequency resolution.

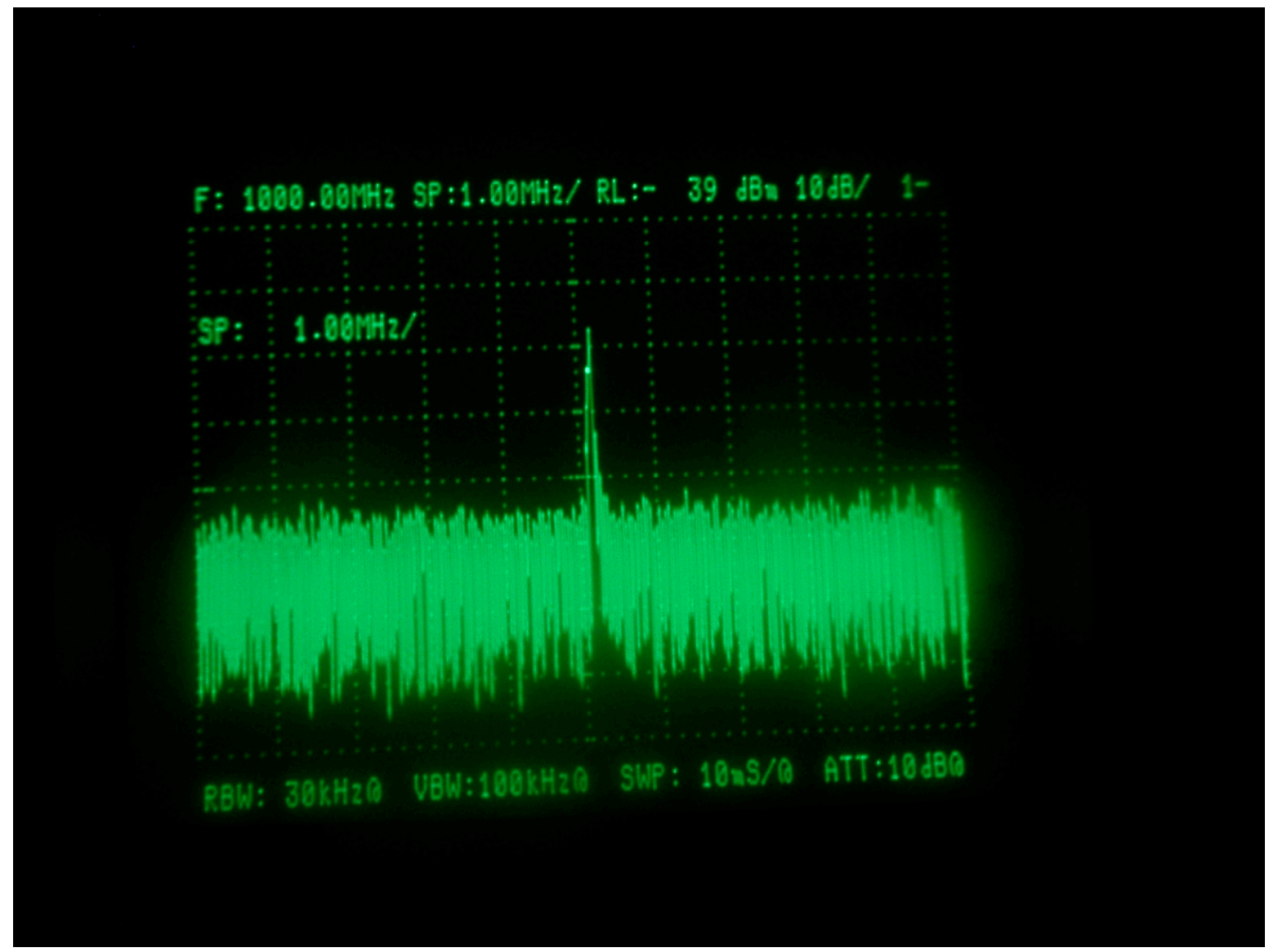

Fig. 7 A frequency spectrum for $\mathrm{TE}_{06}$ mode operation at the second harmonic.

Horizontal: $1 \mathrm{MHz} /$ div. Vertical: log scale.

\section{Conclusion}

A $394.6 \mathrm{GHz} \mathrm{CW}$ gyrotron (Gyrotron FU CW II) is designed for application to $600 \mathrm{MHz}$ DNP/ proton-NMR for sensitivity enhancement, which will be used for analysis of protein molecules. The corresponding frequency for ESR is $394.6 \mathrm{GHz}$. The required output power is several tens to one hundred watts. In addition, high stabilization of frequency and amplitude for long-term $\mathrm{CW}$ operation are also requested. Therefore, such requirements decide the specifications of the gyrotron.

We decided to use a single mode operation of $\mathrm{TE}_{2,6}$ mode at the second harmonic. After the 
construction of the gyrotron tube, it is tested by using an $8 \mathrm{~T}$ liquid-He free superconducting magnet.

Many cavity modes including $\mathrm{TE}_{2,6}$ can operate at both the fundamentals and second harmonics. Among them, several modes at the second harmonics operate in single modes. The output power measured by a water load is distributed in the ranges of 100 to $200 \mathrm{~W}$ for fundamental operations and of 10 to $30 \mathrm{~W}$ for second harmonic operations. The frequencies are also measured by a heterodyne detection system with a synthesizer and a harmonic mixer. All of measured frequencies are lower than the calculated ones by around 0.57 percent. This means that there is the fabrication error of the cavity. The error is also 0.57 percent and the real size of the cavity radius is larger by $14 \mu \mathrm{m}$. As the results, $\mathrm{TE}_{0,6}$ mode (not $\mathrm{TE}_{2,6}$ ) is the best mode for application to $600 \mathrm{MHz} \mathrm{DNP} /$ proton-NMR, because the frequency 394.27 (close to $394.6 \mathrm{GHz}$ ) and the output power is around $30 \mathrm{~W}$. A slight difference between the observed frequency $394.27 \mathrm{GHz}$ ) and the required frequency $(394.6 \mathrm{GHz}$ ) should be cancelled out by adjusting the magnetic field intensity of $600 \mathrm{MHz}$ proton- NMR device.

The quality of the observed frequency spectrum of $\mathrm{TE}_{06}$ mode is quite high and the stability of the frequency is excellent. All of observed cavity modes are useful and available for high power sub- $\mathrm{THz}$ technologies including ESR spectroscopy, DNP/NMR for analysis of protein molecules, plasma scattering measurement and so on.

We are now trying higher voltage operation of the gyrotron FU CW II in order to increase the output power. In the future, we are planning the long term, stable operation of the gyrotron.

\section{Acknowledgements}

This work was carried out as a collaborative research work between Institute of Protein Research, Osaka University and the Research Center for Development of Far Infrared Region, University of Fukui. Japan Science and Technology Agency (JST) supports this work by the SENTAN project for 'Development of System and Technology for Advanced Measurement and Analysis'.

\section{References}

1) M. Thumm, "State-of-the-Art of High Power Gyro-Devices and Free Electron Masers Update 2006," Scientific Report FZKA 7289, Forschungszentrum Karlsruhe, Germany, February 2007

2) G.F. Brand, Z. Chen, N.G. Douglas, M. Cross, J.Y.L. Ma and L.C. Robinson, A tunable 
millimeter-submillimeter gyrotron, Int. J. Electronics 57 (1984) 863-870.

3) S.E. Spira-Hakkarainen, K.E. Kreischer and R. J. Temkin, Submillimeter-wave harmonic gyrotron experiment, IEEE Trans. Plasma Sci., PS-18 (1990) 334-342.

4) T. Idehara, T. Tatsukawa, I. Ogawa, H. Tanabe, T. Mori, S. Wada, G.F. Brand and M.H. Brennan, Development of a Second Cyclotron Harmonic Gyrotron Operating at Submillimeter Wavelengths, Phys. of Fluids B4 (1992) 267-273

5) V.A. Flyagin, A.G. Luchinin, G.S. Nusinovich, Submillimeter-wave gyrotrons: theory and experiment, Int. J. Infrared and Millimeter Waves 4 (1983) 629-637.

6) T. Idehara, T. Tatsukawa, I. Ogawa, Y. Shimizu, and T. Kanemaki, Development of a High-Frequency, Second-Harmonic Gyrotron Tunable up to $636 \mathrm{GHz}$, Phys. of Fluids B5 (1993) 1377-1379.

7) K.D. Hong, G.F. Brand and T. Idehara, A 150-600 GHz Step-Tunable Gyrotron, J. Appl. Phys. 74 (1993) 5250-5258.

8) T. Idehara, S. Mitsudo and I. Ogawa, Development of high frequency, high stable gyrotrons as millimeter to submillimeter wave radiation sources, IEEE Trans. Plasma Sci. 32 (2004) 910-916.

9) T. Idehara, H. Tsuchiya, O. Watanabe, La Agusu and S. Mitsudo, First experiment of a THz gyrotron with a pulse magnet, Int. J. Infrared and Millimeter Waves, 27, pp. 319-331 (2006).

10) V. E. Zapevalov, V. K. Lygin, O. V. Malygin, M. A. Moiseev, V. P. Karpov, V. I. Khizhnjak, E. M. Tai, T. Idehara, I. Ogawa, S. Mitsudo, Development of the $300 \mathrm{GHz} / 4$ kW/CW gyrotron, Proc. of Int. Workshop on Strong Microwave in Plasmas, 1 (2006) pp. 167-172.

11) T. Saito, T. Idehara, S. Mitsudo, I. Ogawa, H. Hoshizuki, H. Murase, K. Sakai, Oscillation Characteristics of CW $300 \mathrm{GHz}$ Gyrotron FU CW I, Conf. Digest of The Joint 31 st International Conference on Infrared and Millimeter Waves and 14 th International Conference on Terahertz Electronics (IRMMW -THz 2006) Shanghai, China, September 18-22, 2006 12) La Agusu, T. Idehara, T. Saito, H. Murase, T. Kanemaki, D. Takahashi, and T. Fujiwara, Design of a CW $395 \mathrm{GHz}$ gyrotron (Gyrotron FU CW II) for sensitivity enhancemernt of NMR spectroscopy, Int. J. Infrared and Millimeter Waves, to be published. 